\title{
RISK ANALYSIS OF THE END USER COMPUTING
}

\author{
Fatemeh Ghotb and Bruce A. Calway \\ Swinburne University of Technology, John St. Hawthorn VIC 3122 Australia \\ fghotb@swin.edu.au/bcalway@swin.edu.au
}

\begin{abstract}
Development of new generation languages and new tools have made it very easy for end users to develop their own applications. This possibility introduces new problems in the end user environments. This paper is an attempt to rank end users according to the risks they generate in the End User Computing (EUC) environments. It is hoped that identification of risk groups would be a useful tool in providing appropriate training programs for the purpose of risk reduction.
\end{abstract}

\section{Introduction}

End Users are managerial, professional, and operating level personnel in functional areas such as production, marketing, finance and human resources who use information outputs from organisation. information systems (IS) in their work activities. Traditionally they have depended on data processing or information departments to design, maintain and run the information systems that provide them with outputs. Over the years, because of the communication difficulties and mismatch between the End User and the analyst understanding of the requirements, End Users have drifted from that tradition to self programming which has become more achievable by the evolution of powerful, yet inexpensive hardware and user-friendly software. This phenomenon is referred to as End User Computing (EUC).

Corporate interest in EUC did not begin in earnest until the personal computers revolution in early 1980's. A survey by Ball and Harris(1982) could not even find EUC among the list of most issues cited by IS managers and professionals. In the past decade however, with the help of easily accessible computing tools, End Users have gained computer literacy, and even expertise and have become more and more independent of the IS departments. A large number of End Users now develop, maintain and use their own IS applications for decision making, with little assistance from IS specialists (Mirani and King,1994). Now a days many managers have become direct users of computer technology in order to capture specific information relating to their jobs and even senior managers are taking their high-power notebooks anywhere they go. This has stemmed from the need to analyse data and develop projections, models, and various kind of what-if analysis(Huysmana, 1994). There is principally a two way sub-division of EUC/IS technology utilisation; first managers and others who have become direct users of computer technology for the reasons just mentioned. The second, are those who for various reasons develop IS applications for personal and corporate use, without necessarily engaging the IS departments of and organisation.

The major advantages attributed to EUC include enhanced productivity of professionals, provision of userfriendly and responsive systems, and overcoming the implementation problems by transferring this process to the users(Nelson,1989). EUC activities are considered to be risk prone and in order to minimise cost associated with the EUC activities, the potential risks should be identified. Alavi and Weiss(1985) define risk as the probability that a financial loss may occur. They as well as Pianko(1988) suggest a framework in which EUC can be employed and controlled effectively. They divide the risks associated with the EUC application System Development Life Cycle into three stages: analysis, design and implementation.

Rockart and Flannery(1983) classify End Users' risks into six distinct categories. Among those categories it appears that the highest risk is associated with the command level users, End User programmers and functional support personnel because of their involvement in the design, programming and operations of their applications.

The provision of End User support appears to be critical to overall IS organisational effectiveness. The purpose of this paper is to serve as a guide to organisations and to the End Users to identify the level of risk associated with EUC tasks within different level of technological complexity, as well as the level of risk associated with individuals in the organisation involved in the EUC activities. Identification of the risk associated with End Users and/or tasks can serve as a useful tool in task assignment and in providing appropriate End User training and support. 
The approach taken here only looks at the higher levels of risk assessment in terms of End Users, IS tasks, technology and organisational infrastructure. No attempt is made at this time to undertake risk assessment at various IS development stages such as analysis, design, etc. The System Development Life Cycle (SDLC) risk assessment approach is further detailed for IS development by Boehm(1991).

\section{Methodology}

In order to assess the risk associated with EUC activities, information about the task complexity and its technological requirements, the available organisational technology, and the individual skills must be obtained. Therefore preparation of three profiles/the organisation/technology profile, the task profile and the End User profile) is deemed to be necessary. The purpose of these profiles is to specify the variables which impact the risk of failure of EUC and to collect related information by means of questionnaires.

\section{The Organisation Profile}

An organisation may have one or more technology scenarios and it is the overall information systems technology architecture which determines the risk associated with any technology selection. Three architectural aspects would require to be measured in order to determine a technology profile:

- Information Systems framework

- Enterprise wide IS architecture

- Development infrastructure.

Gray et al (1994) suggest that such technology variables can be identified and the complexity associated. with that technology quantified. Such quantification could be captured by questionnaires in terms of organisation characteristics, technology (software, hardware, support), information volatility; and organisation policy (architecture, training, etc.)

\section{The Task Profile}

End User applications have been observed as being task oriented by nature. The tasks may require some technological assistance whether as an information resource, application software or information technology. There are three significant variables in terms of tasks which impact the risk of failure. Each task which has a technology requirement will have risks associated with its complexity, type of technology requirement and type of End User profile. In order to prepare a task profile the desire is to capture the variables which determine the task/technology framework in relation to the organisation, the task characteristics in terms of finance, people, internal and external impact, etc. The information would be collected for each task via questionnaires and the information should be given by those who prepare the task descriptions.

\section{End User Skills Profile}

Each individual can be assessed both quantitatively and qualitatively for technology and task knowledge or expertise. It seems reasonable not to assume a single level of knowledge or skill for a particular End User but that the knowledge and skills would be evaluated relative to the interaction of the organisational technology platform and task risk scenario specific at the point in time of the analysis.

The question of qualifications which an End User may possess brings into focus the pre-supposition that being an End User automatically makes that individual a higher risk and therefore the task outcomes being fraught with danger of failure. Assessing the individuals ability to undertake a particular task/technology paradigm focuses the need for training and/or technology framework change. The opportunity also exists to select the resource both human and technological to suit a task profile.

Any combination of End User task/technology profile will have several entries, in that, the End User may be skilled for example at spreadsheet use and finance predictions, or be skilled at data modelling for marketing information. Therefore, the selected End Users could be taken from a wider sampling of End Users within an organisation.

The inverse association of a known End User profile to a task technology requirement would also be a relevant approach. That is where the known End User skills are taken as the first point for selection of an individual or group to progress a particular task. 


\section{The AHP Application}

Since early days of development of the Analytical Hierarchy Process (AHP) by Saaty $(1980,1982)$, it has been applied in numerous internationally in diverse fields. Some of its application in high technology are: selection of applications for robots in space(Bard,1986), workbenching for collection of human knowledge and preferences for storage in knowledge based systems(Boose,1987), selection of a computer operating system(Roper-Lowe and Sharp,1990), and Selection of hospital equipment(Ghotb and Warren, 1995) to name just a few. Not many publication have been cited in the risk assessment using AHP specially in the area of EUC.

The distinguishing features of AHP which make it a useful tool for this application are; its hierarchical structure which makes it easy to determine the relative contribution of each system components towards the over all objective as well as the pairwise comparison of qualitative attributes. For an in depth explanation of the principles and mathematics of AHP, the reader is referred to Saaty $(1980,1982)$.

AHP can be used at three levels in the problem under discussion; The first level is to rank the tasks according to the risk their failure would impose on the organisation. This process is done by preparing a task hierarchy with variables impacting on the risk level as the first level criteria. The skill and technology required for accomplishing the task would be two of the main criteria for the task. A more detailed listing of criteria would obviously be case related. Any general criterion can be decomposed into several sub-criteria to better highlight the variables which affect the risk level. The final level of the hierarchy would be the list of tasks. In order to avoid pairwise comparison of many tasks which might be difficult in some cases, the rating model should be used. Intensity levels for each task can be specified with several levels of risk associated with the task such as: low, medium, high, or with a 1- 9 scale of AHP such that 1 specifies the extreme low level of risk and 9 specifies the extreme high level. Other types of intensity levels could also be introduced according to the need of the task nature.

The second level in which AHP can be utilised in this problem is to rank the organisation technology in terms of risk imposed on the EUC. Within an organisation different technologies could be ranked using AHP. Figure 1 represents a hierarchy used in a simple case study for ranking organisational complexity using organisation profiles. The ranking could be done by pairwise comparison of organisations on each factors using a benchmark.

The task risk then is plotted against the technology framework(figure 2). which is an assessment of the technology risk as that has already been profiled for the organisation (discussed above). Different risk zones could be identified. The task risk profile will form the horizontal axis where far left hand point $(0)$ is associated with the lowest assessed generic risk for a task and the far right hand point (1) is the highest assessed generic risk for a task within that organisation. The 0-1 scale on the axis is in agreement with the output from the rating models. Each point in this graph would identify the risk level associated with each task within a level of technology complexity which it requires.

One can also take the alternative approach of assessing the task risk against the technology which is performed at and then try to locate the optimum location for the task within the organisation. 


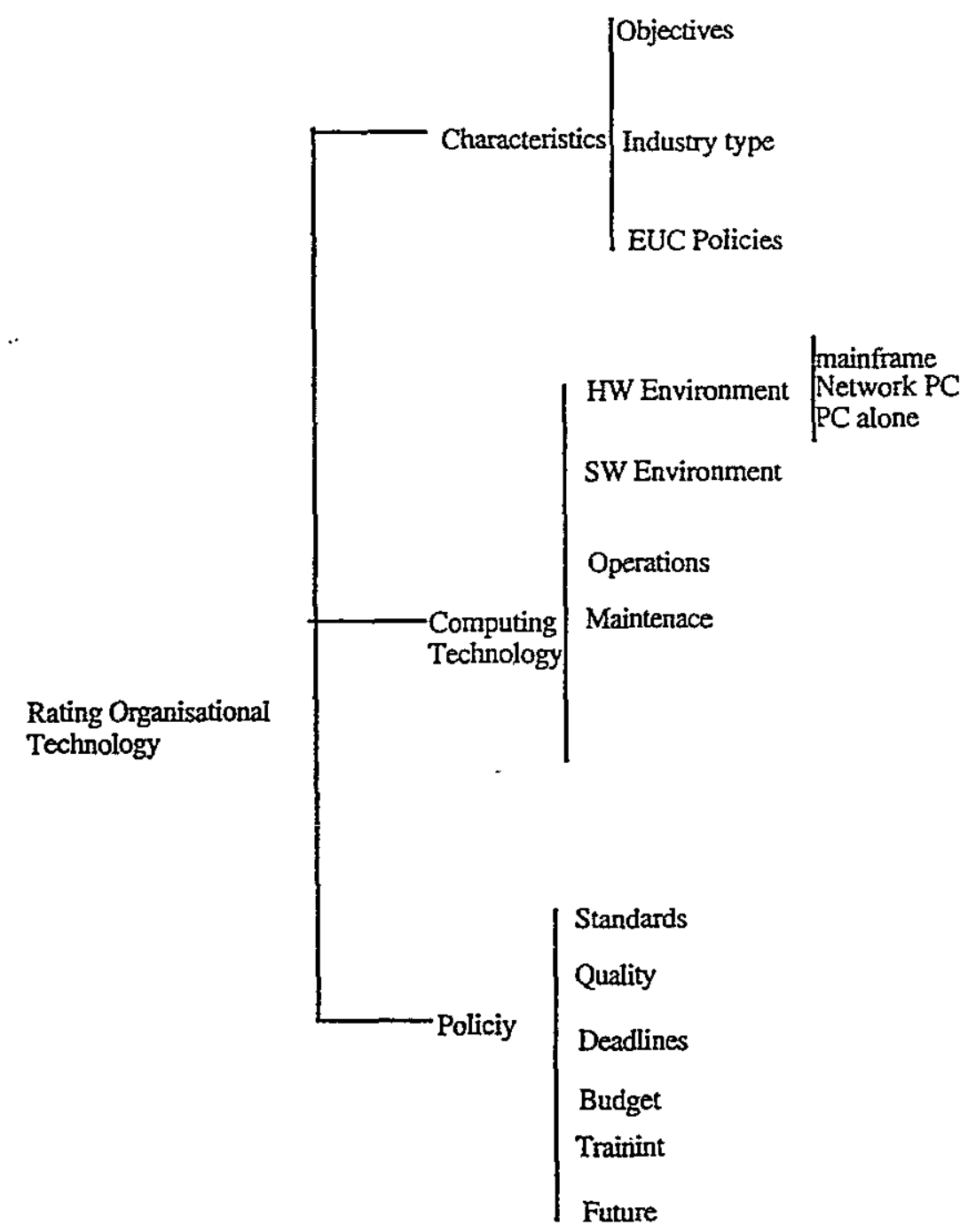

Figure 1. The Hierarchy for ranking organisation technology

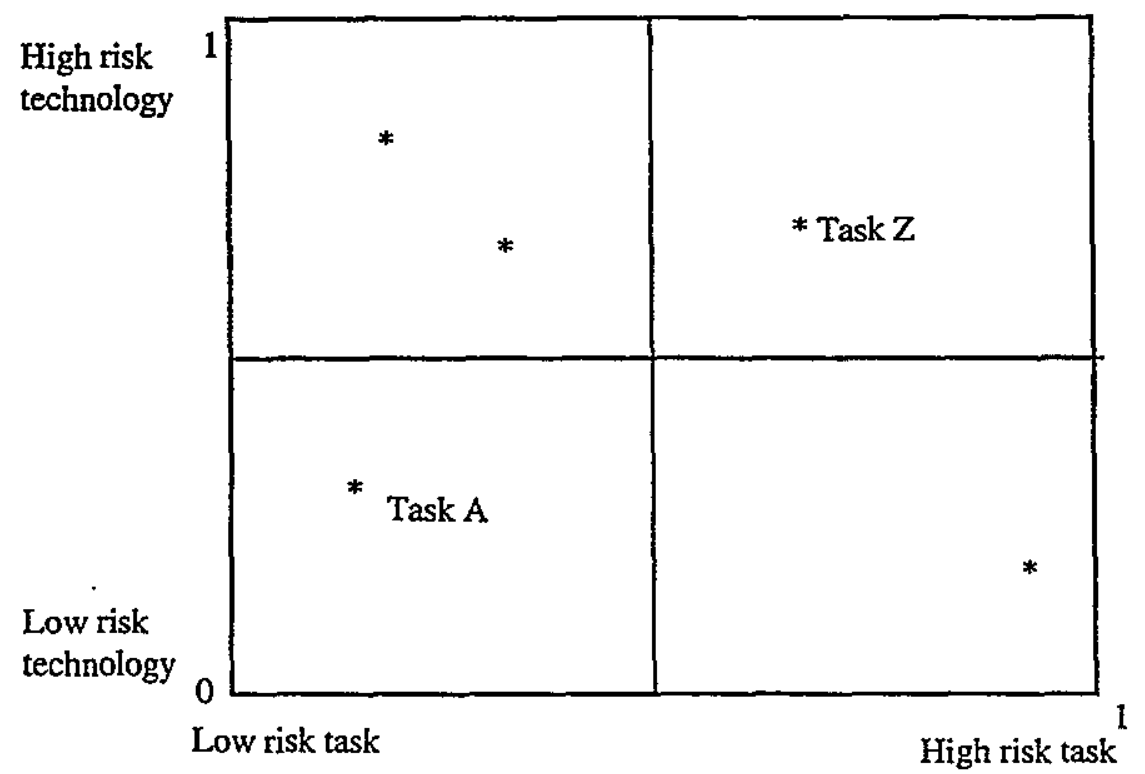

Figure 2. Plot of task risk versus organisation ranking 
The third level in which AHP can be utilised is to rank the End Users' skill profiles. The End Users are ranked with the rating model of AHP according to their skill levels. The result then can be combined as a tripartite relationship graph of task, technology risk and End User skills as shown in figure 3.

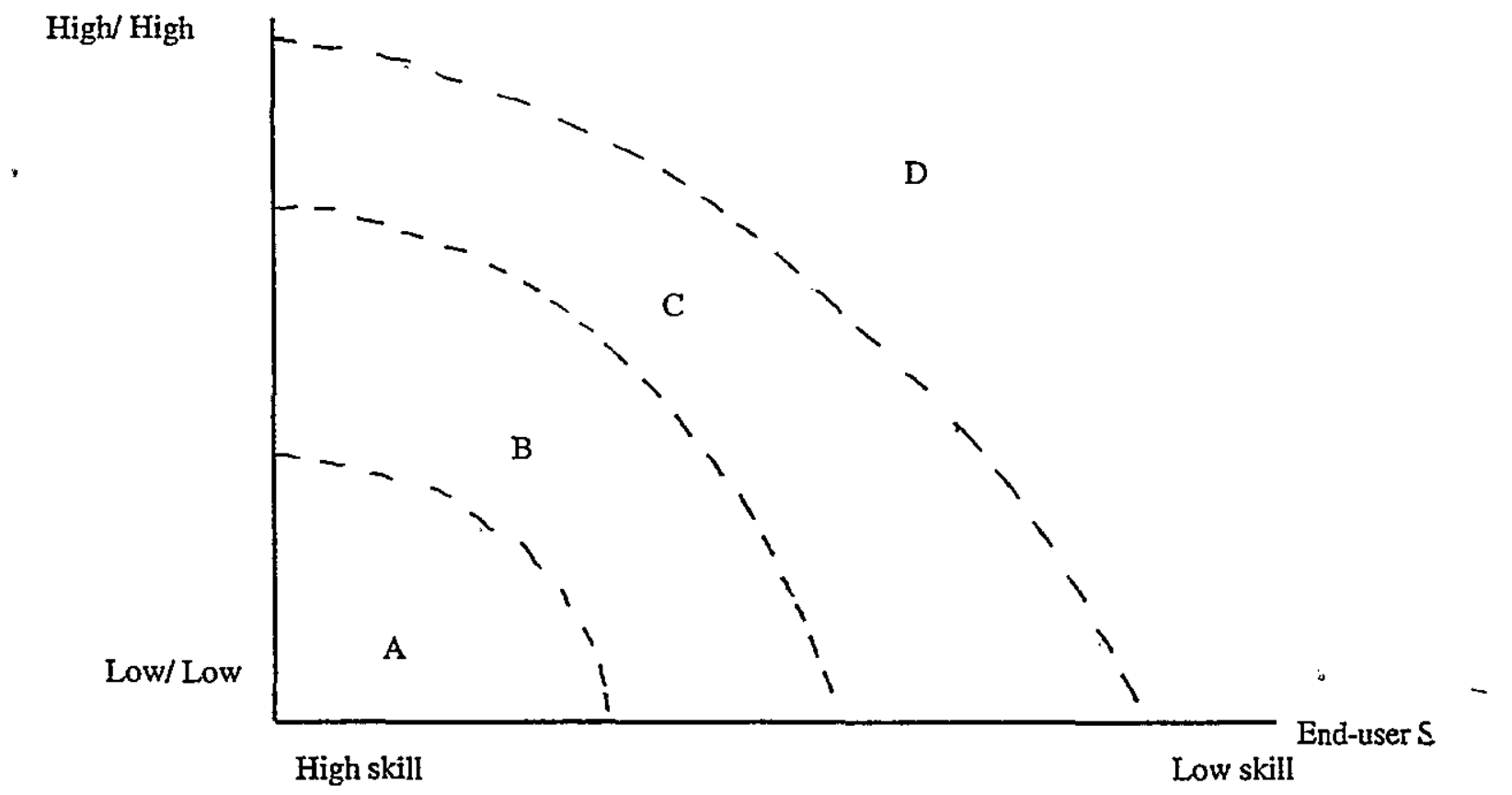

Figure 3. Tripartite diagram of End User/ tas/ technology for different risk groups

The technology/task risks can be categorised in four levels as;

$$
\begin{aligned}
& \mathrm{A}=\text { acceptable risk, } \\
& \mathrm{B}=\text { manageable risk, } \\
& \mathrm{C}=\text { High EUC, task } / \text { technology risk, and } \\
& \mathrm{D}=\text { Extreme EUC, task/ technology risk. }
\end{aligned}
$$

The bands separating categories are specified by experts in the organisation and they can change as the technological structure and tasks' profiles change within the organisation.

\section{Remarks}

The process of the risk assessment is useful at different levels; at a technology / task level because changes may be made to adjust these entities, and at the End User level, as individual competencies may require action in term of training and technology support in order to adjust the End User task/ technology risk towards low risk EUC end of the graph.

A simplified version of the suggested model was used as a student case study. Twenty students from four different departments of the university with varied technological capabilities and requirement were interviewed and questionnaires were filled. AHP hierarchies were prepared and the outputs graphed as explained. Although the case study was somewhat an over simplified case of real situations, it proved the point that the suggested model can serve as a useful tool in minimising risk by proper task to.skill assignment as well as in providing training and support to the groups or individuals within an organisation. 


\section{References}

Alavi, M., and Weiss, I. R. (Winter 1985/86), "Managing the risks associated with End User Computing", MIS, 2/3, 5-20.

Ball, L., and Harris R. (March 1982), "SIMS Members; a Member Analysis", MIS Quarterly, 19-38.

Bard, J. F. (1986), "Evaluating space station applications of automation and robotics", IEEE Transactions on Engineering Management, EM-33/2, 102-111.

Boose, J. H. and Bradshow, J. M. (1987), " Expertise transfer and complex problems: using AQUINAS as a knowledge acquisition workbench for knowledge-based systems", International Journal of Man-Machine Studies, 26/1, 3-28.

Boehm, B. W. (1991) Software risk management, IEEE Computer Society Press, W-DC.

Gray, p. et al (1994) MIS Management of information systems, 2nd ed., Dryden Press.

Ghotb, F., and Warren, L.(1995), "A Case study comparison of AHP and a fuzzy decision analysis", Engineering Economist, 40/3, 233-246.

Huysmans, J. H.(1994), "Using the systems approach to increase management science impact on business", Interfaces, 24/5, 152-164.

Mirani, R. and King W. R.(1994), "The development of a Measure for End User Computing Support", Decision Sciences, 25,14, 481-498.

Nelson, R. R.(1989) End User Computing; Concepts, Issues and Applications, John Wiley, New York.

Pianko R. R.(1988), End User Computing; Management, Applications, and Technology, John Wiley, New York.

Rockart, J. f., and Flannery, L. S.(1983), " The Management of End User Computing", Communicátions of the ACM, 26/10, 776-784.

Roper-Lowe, G. C. and Sharp, J. A.(1990), "The analytic Hierarchy Process and its Application to an Information Technology Decision", 41/1, 49-59.

Saaty, T. L.(1980) The Analytic Hierarchy Process, McGraw Hill, New York.

Saaty, T. L.(1982) Decision Making for Leaders, 1982, Wadsworth, Belmont, CA. 